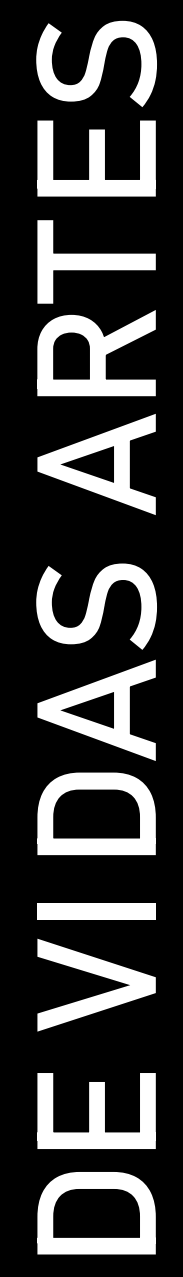

PAULA GUERRA E LÍGIA DABUL (EDS.) 


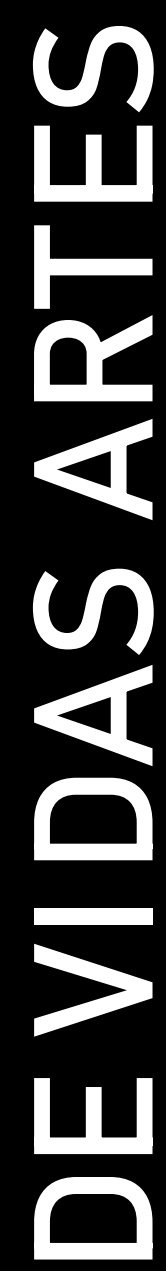

\section{PAULA GUERRA E LÍGIA DABUL (EDS.)}

Design por Irandina Afonso

Ilustração da Capa por Lua Celina

Publicado em Setembro 2019

Universidade do Porto. Faculdade de Letras

[University of Porto. Faculty of Arts and Humanities]

Porto, Portugal

ISBN 978-989-8969-18-7

Suporte: Eletrónico - Formato: PDF / PDF/A 


\title{
I.3. Amontoado de destroços: a trajetória de Miguel Rio Branco via imagens e montagens artísticas
}

\section{I.3. Heap of debris: Miguel Rio Branco's trajectory via artistic images and montages}

\section{Diego Soares Rebouças}

\begin{abstract}
Resumo
A presença de clivagens e bifurcações nas elaborações discursivas sobre imagens, especificamente sobre imagens artísticas no contexto das rupturas e polêmicas causadas pela arte contemporânea, é lugar-comum nas pesquisas e discussões acadêmicas nos campos da Arte, da Imagem, da História, da Sociologia (da Arte) etc. A questão das elaborações de arte contemporânea e o papel das imagens, sobretudo em instalações artísticas, tomam lugar nas linhas que seguem balizadas, sobremaneira, na vida e na obra de Miguel Rio Branco. Essa pesquisa nos apresentou de que forma a sobreposição de camadas materializadas nas imagens de arte de Miguel têm a faculdade de constituir os traços primordiais de sua trajetória artística.
\end{abstract}

Palavras-chave: Miguel Rio Branco, trajetória de vida, arte contemporânea, imagem.

\begin{abstract}
The presence of cleavages and bifurcations in the discursive elaborations on images, specifically on artistic images in the context of the ruptures and controversies caused by contemporary art, is common place in the researches and academic discussions in the fields of Art, Image, History, Sociology ( of Art), etc. The question of the elaboration of contemporary art and the role of images, especially in artistic installations, take place in the lines that are marked, especially, by the life and work of Miguel Rio Branco. This research showed us how the 'overlapping of layers' materialized in Miguel's art images have the ability to constitute the primordial traits of his artistic trajectory.
\end{abstract}

Key words: Miguel Rio Branco, life trajectory, contemporary art, image.

\section{Introdução}

A escolha pela trajetória de Miguel Rio $\mathrm{Branco}^{30}$ e pela experiência de imersão na sua obra, justifica a metodologia de construção da presente proposta textual na medida em que se buscou apreender, tanto na história de vida, quanto no processo de feitura das instalações do artista, produtos do acúmulo das experiências e flanagens nas órbitas do campo artístico pelos quais passou no decorrer de sua trajetória. E para além disso, o próprio conceito

${ }^{30}$ Este capítulo resulta do desenvolvimento do mestrado do autor intitulado "Amontoado de destroços: Reflexões sobre comunicação e arte contemporânea a partir da instalação 'Entre os olhos, o deserto', de Miguel Rio Branco" no Programa de Pós-Graduação em Comunicação da Universidade Federal do Ceará sob orientação científica dos Professores Doutores Silas José de Paula e Kadma Marques Rodrigues. 
imbricado no que se pode chamar de arte contemporânea, manifestações que seriam fusões de disciplinas particular e formalmente heterogêneas, conduznos a considerar o trabalho de Rio Branco um representante singular do gênero.

Partimos da prospecção de que o espaço de exposição e seus elementos imagéticos se tornam possíveis pela construção de elos que estão aquém e além da dimensão espacial e formal, constituindo-se em uma estética do encontro e das relações, na qual se pode adentrar na vida mesma do autor. O estudo de trajetórias de vida nas Ciências Sociais como método de pesquisa tem permitido problematizar acerca de fenômenos sociais sendo a arte um deles - possibilitando perceber até onde pode chegar o pesquisador que parte da coleta e da análise de materiais acumulados relativos a histórias de vidas, no caso, de artistas.

Visitar a página Web do artista torna-se uma experiência inicial de conhecimento e impacto acerca de Miguel, chamando a atenção pela estética destrutiva, visceral e com programação visual, semelhante aos seus projetos expográficos, em formato modular: vários de seus trabalhos assemelham-se a mosaicos que optam pelo recurso da montagem como linguagem artística. Antes mesmo de navegar pelas seções do site, o público pode se deparar com uma animação de abertura: um aglomerado de imagens que parecem cartas rapidamente colocadas na mesa, sobrepostas de forma desordenada, acumulativa e frenética.
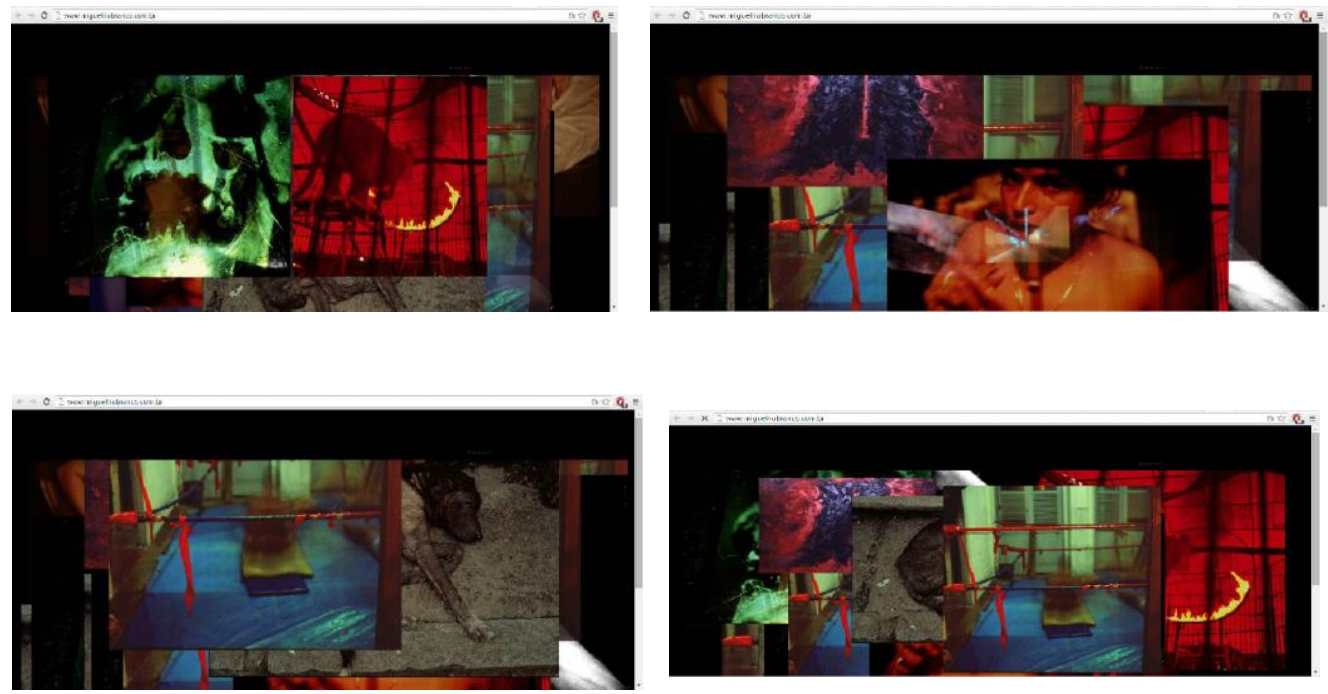

Figuras I.4.1: Imagens gravadas aleatoriamente com a tecla de captura (print screen) acerca da animação de abertura/apresentação do Website de Miguel Rio Branco

Fonte: http://www.miguelriobranco.com.br/ 
Miguel Rio Branco trabalha com o excesso, com amontoados, com o que está para além das bordas, das arestas; com o que sobra: acúmulos, dejetos, expurgos. Nesse movimento, acaba por criar uma gramática que nem sempre é alcançada pelo grande público - talvez isso seja mais outro aspecto da arte contemporânea - pois afirma privilegiar um "discurso imagético, com poética própria", em detrimento daquele de caráter mais literal, já que não pensa "numa narrativa com começo, meio e fim", mas se identifica mais com o discurso artístico "sem uma construção tão linear" (Persichetti, 2008: 2223).

No percurso da pesquisa fez-se necessário ocupar espaços de exposição tantos quantos fossem possíveis e acessíveis na busca do contato com ao trabalho de Miguel Rio Branco, especificamente as instalações artísticas. Nesse sentido, o Instituto Inhotim - museu de arte contemporânea a céu aberto em proporções colossais - passou a ser um dos principais campos de pesquisa, já que agrupa diversas obras instaladas ao ar livre e mais de vinte galerias de artistas nacionais e internacionais. É ali onde há um pavilhão permanente dedicado a Miguel Rio Branco (Figuras I.4.2), local que abriga diversos de seus trabalhos.
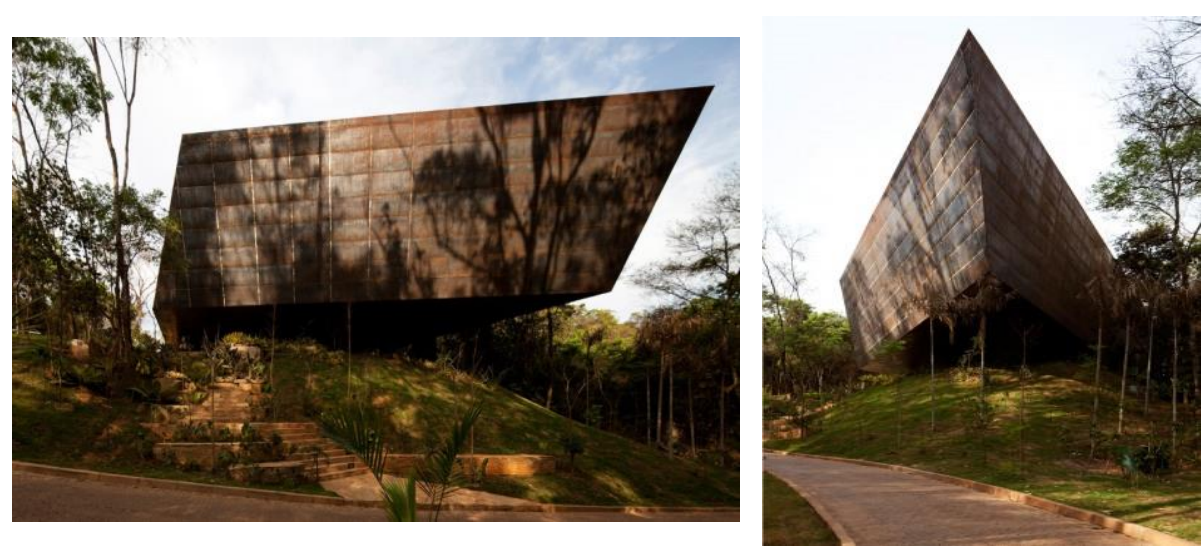

Figuras I.4.2: Pavilhão Miguel Rio Branco no Instituto Inhotim, Brumadinho - MG:

Perspectiva lateral e frontal, respectivamente

Fonte: https://www.archdaily.com.br/br/01-7103/galeria-miguel-rio-branco-inhotim-arquitetos-associados

A instalação, linguagem artística etérea e voluptuosa, de tentáculos que se multiplicam a cada novo experimento, cria espaços físicos e relacionais. Nela, as imagens criam um corpo robustecido - não apenas no sentido que tange à noção de força ou de vigor - que se enlarguece por causa das inúmeras camadas que acumula. Um corpo inchado de tanto 
convergir/acumular temporalidades que deixam suas largas marcas: um verdadeiro amontoado de destroços, uma acumulação de restos, que se ressignifica pelo olhar. Desde o início da década de 1980, e mediante o acúmulo de experiências que sua carreira de artista proporcionou, Miguel Rio Branco adentra ao terreno desenhado pela arte conceitual que alcança o Brasil naquelas décadas de 1970 e 1980. Os trabalhos de artistas como Lygia Clark, Cildo Meireles, lole de Freitas, Amilcar de Castro e Hélio Oiticica, além dos de Miguel Rio Branco, passam a propor rupturas com as ideias normativas de obras de arte, valorizando mais o conceito, as ideias e os processos de concepção da obra, do que o objeto e sua representação física.

Passou-se a priorizar o uso de novas tecnologias e a convergência de suportes e linguagens num mesmo trabalho artístico, fazendo das salas de exposição não mais apenas ambientes para receber obras artísticas e os respectivos públicos, mas o espaço expográfico passou a compor a obra em si, como também os públicos passaram a ser parte integrante das manifestações artísticas. No caso de Miguel, passar a conceber e realizar instalações significou, como veremos, a culminância de um uso processual e sistêmico da imagem. $O$ artista adentrou tanto às possibilidades de uso de suas imagens que passou a privilegiar sobremaneira as imagens que já tinha em arquivo, o que acabou por fazer delas representações vivas de sua própria forma de pensar: pensar por imagens. Ali estavam fragmentos de sua própria existência, sua forma de expressar o estar no mundo e também de falar ao mundo sobre questões problemáticas utilizando as imagens dele mesmo. Assim, as fotografias, os vídeos, as instalações de Miguel Rio Branco tornaram-se representantes mesmo de sua subjetividade, objetivadas pela câmera que lavava consigo, o instrumento tradutor de seu olhar, de sua percepção. Desse modo, o enfoque biográfico tornou-se uma necessidade metodológica na qual se buscou um esforço sociológico de situar uma determinada trajetória de vida frente às condições concretas de existência relativas a ela, no caso a trajetória de Miguel Rio Branco.

\section{Sobre Miguel, sua trajetória e suas imagens}

Miguel da Silva Paranhos do Rio Branco (Figura l.4.3) é um destacado e reconhecido fotógrafo/artista brasileiro residente no Rio de Janeiro. Filho autêntico de terras espanholas: Las Palmas de Gran Canária é o município espanhol onde nasceu em 1946. Apesar de ter passado por diversos países como Argentina, Portugal, Suíça, Estados Unidos, foi no Brasil em que se 
firmou, desde o início da década de 1970, e onde mora até hoje. Comunmente é tido como fotógrafo, mas prefere ser tratado como um artista plural, pois tanto destaca ter sensibilidade e atuação em diversas áreas do campo, já que sua produção artística passa pela pintura, pelo cinema, pelas instalações artísticas multimídia, além da fotografia, o leitmotiv de seu trabalho.

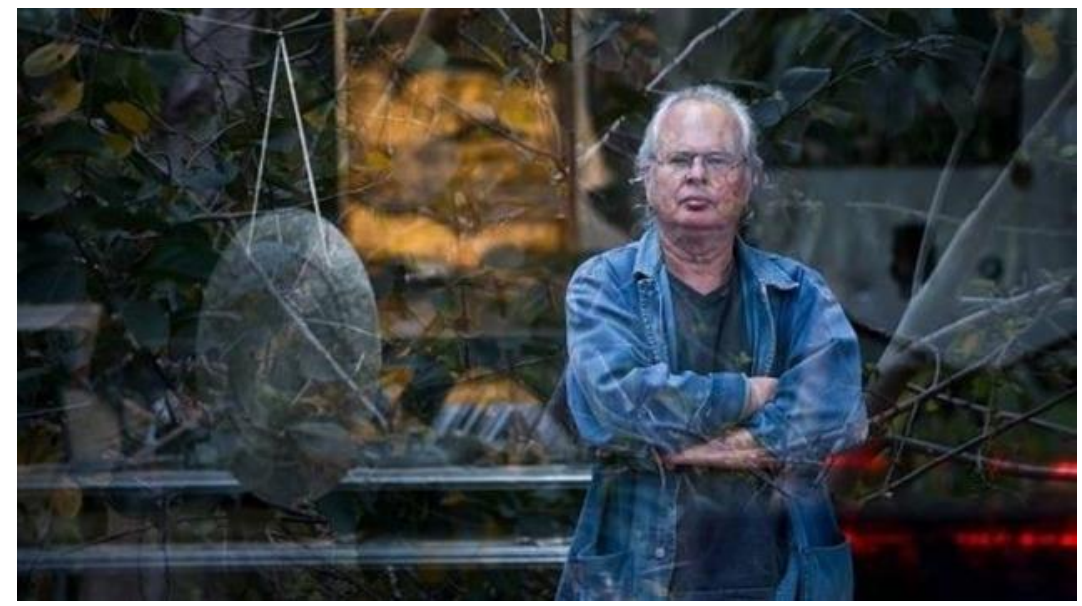

Figura I.4.3: Miguel Rio Branco em sua residência em Araras - Rio de Janeiro, na ocasião de entrevista concedida à ARTE! Brasileiros, em 2011

Fonte: https://artebrasileiros.com.br/arte/miguel-rio-branco-marginal-na-essencia/

Antes de firmar residência no Brasil, Miguel Rio Branco foi alfabetizado em Portugal, depois veio ao Brasil por pouco tempo e em seguida foi para a Suíça - onde começou a pintar no Instituto Flaureamont. Foi aí, resultado dos estudos de desenho e pintura do colégio em Genebra, que começou a preparar-se para sua primeira exposição, numa galeria em Berna, na Suiça ${ }^{31}$, no ano de 1964, aos 18 anos. Em 1966 estudou no New York Institute of Photography, quando morou nos Estados Unidos (1964 - 1967). Já em 1968, de volta ao Brasil, estudou na Escola Superior de Desenho Industrial (ESDI), no Rio de Janeiro, quando de fato afirma ter tido bastante contato com "o pessoal das artes plásticas"32.

Um fato torna-se historicamente relevante e comunmente mencionado por Miguel Rio Branco nas entrevistas em que tem oportunidade de falar sobre o assunto: seus estudos na ESDI, em 1968, foram interrompidos devido ao cenário e às questões sociopolíticas que se avizinhavam ao cotidiano brasileiro. As constantes manifestações em protesto contra as rígidas

\footnotetext{
${ }^{31}$ Cf. página do escritório de arte do paulista James Lisboa, no endereço:

http://www.escritoriodearte.com/artista/miguel-rio-branco/

${ }^{32}$ Trecho de entrevista concedida em 2011 à ARTE!Brasileiros. Cf.

https://artebrasileiros.com.br/arte/miguel-rio-branco-marginal-na-essencia/
} 
medidas do governo militar brasileiro - que culminaram com o Ato Institucional-5 - obrigaram algumas instituições a embargar suas atividades. Entre elas, a ESDI, com a proposta de se reestruturar o currículo readequando-o às necessidades brasileiras de então. Apesar de não se envolver diretamente com os levantes populares, por se considerar muito individualista, o filho de diplomata esteve, ainda assim, envolvido com o clima de acirramento e disputas que se instalou no Brasil daquele período, tendo seus sentimentos de repulsa resvalados para sua produção artística/visual. Alguns anos depois, em 1972, após voltar de nova temporada nos Estados Unidos (1970 - 1972), já se podiam ver os primeiros passos da produção fotográfica e cinematográfica do artista. Em 1990 empreende seus primeiros trabalhos em forma de instalações artísticas.

O artista também tem uma grande afinidade com as paisagens naturais, motivo pelo qual seu ateliê, um grande espaço viabilizado para seus experimentos, localiza-se num recanto do Rio de Janeiro (Araras - o distrito ecológico de Petrópolis) que o coloca em contato com o estado mais puro possível do ambiente natural, ao mesmo tempo em que proporciona um isolamento desejado, segundo afirma. Ali construiu e até hoje preserva um labirinto, projetado nos jardins da casa onde mora. É importante frisar a impossibilidade, durante esse percurso de pesquisa, de uma entrevista presencial com Miguel Rio Branco que contemplasse questões mais específicas no tocante ao interesse dessa investigação. Porém, trabalhos biográficos $^{33}$ tais como livros e dissertações, mas também entrevistas realizadas por sites e revistas especializadas nos últimos anos, bem como as informações contidas em sua página $W e b^{34}$ foram fundamentais para desenhar este escopo. Entretanto e sobretudo foi na elaboração e existência do seu arcabouço artístico e no imaginário que o povoa, manifesto em diversas formas de linguagem, que encontramos suas preferências e os traços do seu percurso. As pesquisas com fontes visuais trilham rumos diversos do convencional, e segundo o historiador Charles Monteiro (2013), em Pensando sobre História, Imagem e Cultura Visual,

o trabalho com e sobre imagens é um grande desafio para os profissionais treinados em interpretar documentos e narrativas escritas, pois os processos de produção das imagens, os circuitos de circulação, as instâncias de legitimação

\footnotetext{
${ }^{33}$ Cf. livro Miguel Rio Branco (2008) de Simonetta Persichetti; a dissertação de mestrado Imagem-poema: A poética de Miguel Rio Branco (2005) de Lívia Afonso de Aquino da Unicamp e diversas outras fontes que citarei ao longo do texto encontrados em sites da web.

${ }^{34} \mathrm{Cf}$. http://www.miguelriobranco.com.br.
} 
e as suas formas de consumo não Ihes são totalmente familiares (Monteiro, 2013: 3).

Dessa forma, o caráter desafiante desta pesquisa residiu, desde o começo, no fato de presumir a possibilidade da montagem de uma biografia construída por imagens, pelas imagens produzidas por Miguel, no caso, sem vilipendiar, entretanto, as fontes literárias já citadas. De que material são feitas suas imagens, seu imaginário e cada momento histórico de sua vida (de artista)? Observar o que o influencia e o que move seu fazer artístico; descobrir o que o afeta, o incomoda e o satisfaz; adentrar ao porquê de ser tido como artista contemporâneo; saber de que forma se relaciona com os contextos históricos, sociais e de mercado de suas experiências de vida foram pontos de partida para um panorama balizador da elaboração de um percurso social de sua obra. Pela multiplicidade de eixos nos quais a arte hoje se ramificou, tornando inviável definir pólos categóricos opostos e bem definidos, há uma notória coexistência espaço-temporal de possibilidades múltiplas para o fazer artístico que constituem um ambiente no qual

As querelas não dizem mais respeito somente a questões estéticas de avaliação
('É mais ou menos bonito ou bem-feito') ou de gosto ('gostamos mais ou menos'),
mas à questões ontológicas ou cognitivas de classificação ('É ou não é arte) e
de integração ou exclusão ('Elevamos ou não determinada proposta ao título de
obra de arte?') (...) Consequentemente, não estamos mais numa lógica
normativa contínua, que estabelece graus de qualidade estética, mas numa
lógica classificatória descontínua que permite determinar posições de
entrosamento ou exclusão (Heinich, 2008: 180-181).

É importante lembrar que os pontos levantados por Heinich (2008) revelam a existência e a exequibilidade de parâmetros que, no caso da arte pós-moderna ou contemporânea, visam legitimar ou desqualificar obras e/ou artistas em um campo que diz respeito à atuação de atores sociais e instituições que funcionam para validar os trabalhos de outrem, e é o que garante a circulação da obra de artistas, e consequentemente a construção e manutenção de suas carreiras junto ao circuito artístico.

Miguel Rio Branco ocupa um lugar no panteão da arte contemporânea. Isso a historicidade de seu trabalho atesta e reforça. Mas torna-se relevante entender o que - ou seja, fatores externos a ele - o permitiu e o permite manter-se como artista consagrado para o âmbito das artes e para o mercado, pois diante das reações de rejeição que esse tipo de manifestação artística tem causado nos públicos devido, entre outros fatores, à quase ausência de beleza normativa comum às obras de arte de outrora, entende-se que é preciso haver suporte de validação que torne um artista, um artista 
(relevante), pois tanto mudanças e descontinuidades por um lado, quanto a manutenção de critérios por outro, são construídos histórica e socialmente, já que são resultado de tomadas de posições.

Um aspecto fundante e talvez elucidador da persistência de atuação da produção artística de Miguel Rio Branco como artista contemporâneo é sua relação com a fotografia, por um lado tão presente nas manifestações multidisciplinares da arte contemporânea; por outro, perpassando sua carreira de uma maneira geral e dorsal: uma espécie de língua materna é a linguagem fotográfica na obra de Miguel. Em entrevista a Simoneta Persichetti (2008), Rio Branco afirma ter começado fazendo fotos no intuito de documentar e observar, pois tais registros tanto Ihe ajudavam na criação das telas, servindo de referências, como também eram usadas como objetos de colagens que se misturavam a outros elementos dos quadros (Figuras I.4.4). O que não quer dizer que Miguel sinta-se à vontade para ser tratado exclusiva ou preferencialmente como fotógrafo: "...as pessoas têm uma tendência de me levar para a fotografia, quando, na verdade, comecei com a pintura ${ }^{35 ",}$ diz.
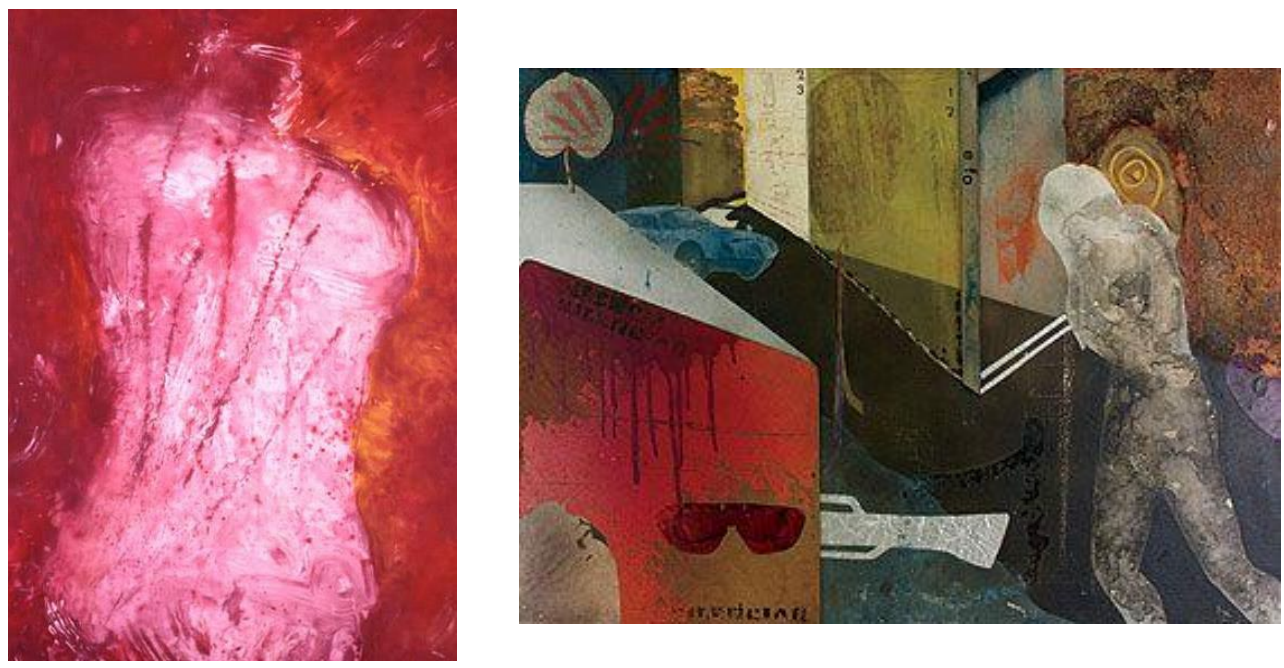

Figuras 1.4.4: Tela Sem Título 1 (ano e técnica não informados) e Tela Cidade Ensaio n.으 2 (1967, Óleo e colagem sobre tela), respetivamente

Fonte: http://miguelriobranco.com.br/portu/comercio2.asp?flg_Lingua=1\&flg_Tipo=P E https://www.catalogodasartes.com.br/obra/BPADA/, respectivamente.

\footnotetext{
${ }^{35}$ A entrevista completa, realizada por ocasião da abertura de sua mostra Teoria da Cor em abril de 2014 na Estação Pinacoteca - SP, pode ser conferida na página web http://cultura.estadao.com.br/noticias/geral,miguel-rio-branco-enfatiza-conexoes-da-fotografia-comoutras-areas, 1158212
} 
Na pintura, aponta para a admiração que nutriu ainda adolescente pela obra de Francisco de Goya ${ }^{36}$ (1746 - 1828), seu conterrâneo, do qual, segundo Persichetti, Miguel "talvez tenha apreendido a contundência" (2008: 8) (Figuras I.4.5). Um traço contundente do trabalho artístico de Miguel Rio Branco se apresenta na forma como trabalha a cor. A manipulação de nuances e matizes (quer seja na pintura, na fotografia ou no cinema), sobretudo privilegiando uma cor determinada, por vezes, na edição de suas imagens fotográficas, diz muito de sua relação com o mundo ao redor. Trabalha saturações com destreza e, com tal recurso, protagoniza uma insistência lancinante que lhe ocorre como forma estética e política de falar ao mundo sobre o mundo. As cores exuberantes que parecem gritar apontam para a presença da subjetividade de seus personagens, mas também a sua, pois uma marca recorrente é a fusão de interesses: de um lado a denúncia e o desejo de dar lugar a determinados temas que tocam questões práticas; de outro, a liberdade para estetizar temas e reelaborá-los conforme seus anseios artísticos. O resultado desse amálgama é uma prova documental a favor tanto do fotógrafo quando da questão evidenciada pelas suas objetivas.
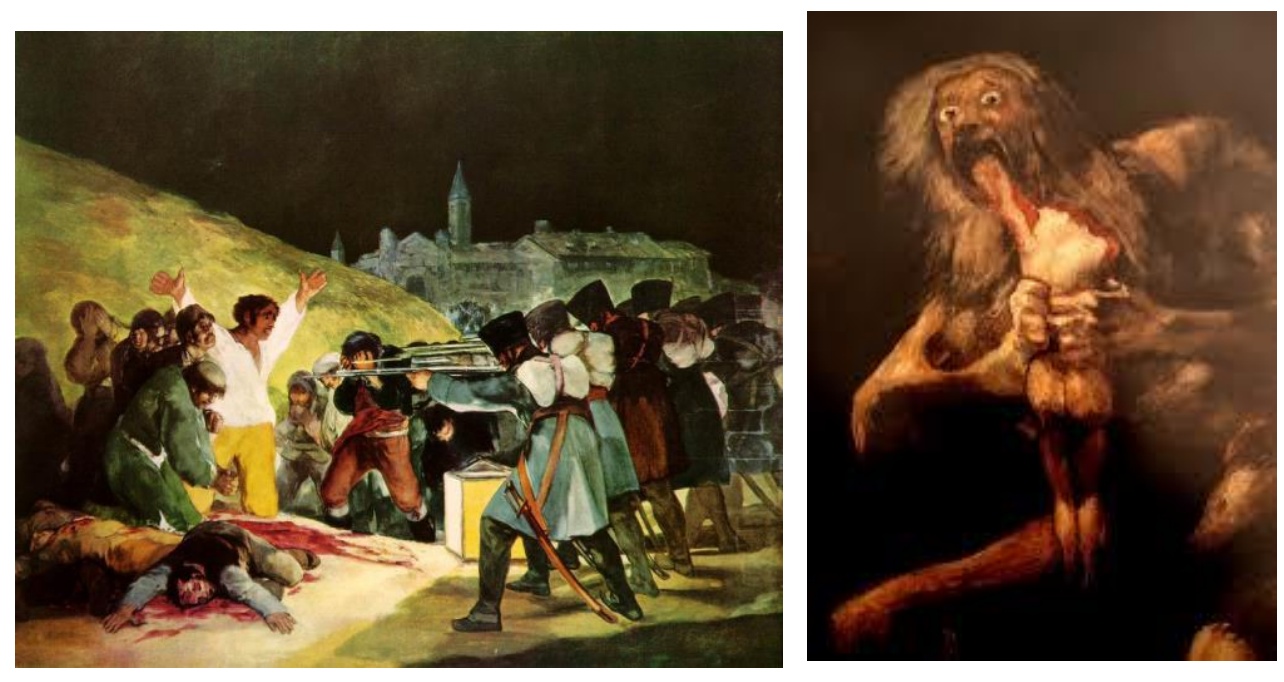

Figuras I.4.5: Tela Los fusilamientos del tres de mayo de 1814 e Tela Saturno devorando a un hijo de 1819

Fonte: https://culturaeviagem.wordpress.com/2013/10/06/as-principais-pinturas-dos-maiores-pintores-igoyal

\footnotetext{
${ }^{36}$ Francisco José de Goya y Lucientes, nascido em 1746 na cidade de Fuentedetodos, em Aragão na Espanha, foi um gravador e pintor destacado por estampar, dentre outros temas, as cenas da Guerra Peninsular, nas quais imprimiu a dramaticidade de um romantismo heróico. Cf. Os Desastres da Guerra, uma série de 82 gravuras feitas entre 1810 e 1814 em: http://goya.unizar.es/InfoGoya/Obra/Grabado.html, página web dedicada a Goya, criada pela Universidade de Saragoça.
} 
Esse trabalho meticuloso da cor nas suas fotografias, além de ser indício de um olhar virtuoso, é, certamente, uma influência da pintura, e foi, por certo, uma alavanca para o desenvolvimento de sua aptidão latente em fazer montagens.

O que me levou para a cor foi a facilidade da edição do cromo, que é uma matriz que você não tem que ficar manipulando ou retrabalhando como o preto e branco... Você seleciona o que tem de melhor e joga fora o que não presta. Então isso me dava uma maior maleabilidade, também pelo fato de estar sempre mudando de lugar... Bastava uma mesa de luz e você construía e constrói facilmente em termos de conexão de imagens. Mas além dessa parte prática a cor para mim era e é uma contemplação, uma informação a mais que torna a imagem mais complexa. E é claro, a conexão com a pintura (...) A cor veio junto com o preto e branco, então nunca comecei com um ou com outro. Comecei junto. Talvez seja complicado porque coloca uma dificuldade a mais: não é qualquer cor que serve para qualquer imagem (Persichetti, 2008: 16).

Essa relação que Miguel Rio Branco mantém com os volumes que a cor cria nas imagens se configura como o cerne de sua atividade de sobreposição de camadas, um traço persistente no seu trabalho artístico: camadas de tinta óleo, em um primeiro momento de sua vida, depois, camadas de cenas, de projeções, de luzes, de trilhas sonoras, de tecidos, de papelões, de vidros, de olhares, enfim, camadas de imagens, que na verdade, afetaram primeiro o seu olhar e se transmutaram como produto do seu imaginário, para depois figurar na sua obra. Por isso, neste trabalho, concebese as produções de Miguel Rio Branco como amontoados de sensações, aglomerados de destroços, de fatias perceptivas, de lascas de pensamento, acúmulo de experiências. Um convite para invadir reentrâncias e adjacências que as obras sugerem ter. A criação de um ambiente de perspectivas transversalizadas, em que somos conduzidos, inclusive, ao que não está diante dos olhos.

A obra de Miguel, não raro, apresenta-se como trabalho etnográfico, pois apesar de carregar em si as camadas propostas pelo artista na construção de um discurso estético peculiar, não deixa de ser referente de fatos e acontecimentos que têm repercussão nos modos de vida de indivíduos e/ou grupos. Visto de outro modo, o que Miguel Rio Branco comunica com suas imagens de maneira prosaica, acaba por denunciar elementos que permeiam o imaginário brasileiro, sobretudo aquele que, no mais das vezes, parece passar despercebido, como se não existisse, mas que é tão familiar e enraizado. A sua abordagem do feminino em diversos trabalhos ou mesmo questões de gênero; a problematização entre esfera pública e esfera privada; a série que retrata o cotidiano da comunidade do Maciel, que veremos a seguir, são exemplos que apontam para essa hipótese. Para ele, a concepção 
criativa de um trabalho está relacionada ao "processo de fazer um quadro mesmo. São camadas que vão sendo feitas, de tentativas, reconstruções" (Persichetti, 2008: 17). O artista acredita que um bom trabalho deve partir de uma base minimamente conceitual, mas que a própria feitura, a vida e as experiências é que vão the dando corpo.

Nesse ínterim, e talvez por causa do destaque na fotografia documental que criava, nas mãos (e pelos olhos) de Miguel, camadas que davam mais volume às imagens, sobretudo por meio do uso de saturação das cores, o fotógrafo chamou a atenção da Agência Magnum ${ }^{37}$, em Paris, a qual passou a compor, em 1980, como fotógrafo correspondente, mas com a exigência pessoal de não ter que engessar-se em parâmetros datados da fotografia jornalística:

\begin{abstract}
A Magnum sempre deu ênfase à visão pessoal e hoje em dia ainda mais pelo fato de a fotografia ter se dirigido para a área de artes plásticas. E o mercado fotojornalístico está em franca queda; qualquer um com seu telefone consegue fotografar ou fazer um vídeo de um desastre acontecendo ao seu lado (...) Meu primeiro contato com eles foi em 1972, eu tinha morado em Nova York dois anos e ia voltar para o Rio. Alguém me falou de dar um pulo na Magnum. Eu nem sabia quem era Cartier Bresson ou qualquer outro fotógrafo conhecido (...) Em 1980, passando por Paris, mostrei o trabalho das ruínas humanas e arquitetônicas do Maciel (...) e acabei me tornando um correspondente da Magnum no Brasil. (Persichetti, 2008: 12).
\end{abstract}

$\mathrm{Na}$ mesma entrevista, Miguel esclarece que antes mesmo de ser convidado para compor o quadro de fotógrafos da agência, ainda tentou, por ocasião de uma estada em Paris, tornar-se um membro, o que eles chamam de nominee. Entretanto, isso significaria estar sob a égide dos protocolos e exigências do fazer fotográfico daquela organização. Ainda assim, Rio Branco tentou fazer-se associado a partir do trabalho fotográfico que desenvolvera com os índios Kayapó da aldeia de Gorotire (PA) (Figuras I.4.6), mas o primeiro ano de tentativa fora frustrado para o ingresso como associado. Contudo, outras oportunidades surgiram a partir da repercussão desse mesmo trabalho fotográfico. Isso fez Miguel tomar a decisão de voltar ao

\footnotetext{
${ }^{37}$ Trata-se de uma cooperativa francesa de fotógrafos. Na descrição de Henri Cartier-Bresson, "A Magnum é uma comunidade de pensamento, uma qualidade humana compartilhada, uma curiosidade sobre o que está acontecendo no mundo, um respeito pelo que se está a passar e um desejo de transcrever isso visualmente." (Livre tradução de: "Magnum is a community of thought, a shared human quality, a curiosity about what is going on in the world, a respect for what is going on and a desire to transcribe it visually."). Para mais informações cf.

http://www.magnumphotos.com/C.aspx?VP3=CMS3\&VF=MAX_2\&FRM=Frame:MAX_3\#/CMS3\&VF=MAX_ 2\&FRM =Frame:MAX_5
} 
Brasil em definitivo, quando então é que se torna correspondente da agência, o que Ihe traria mais liberdade no trabalho de produção imagética.
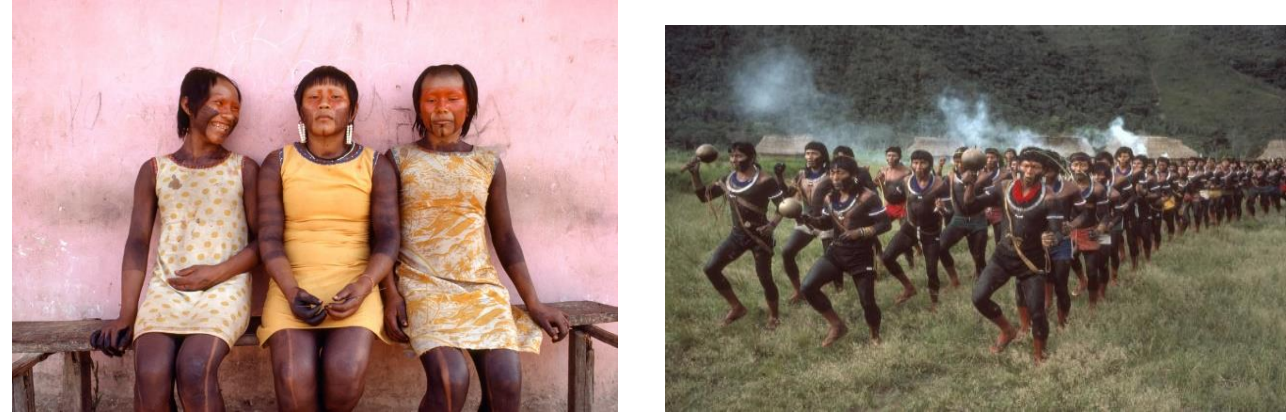

Figuras I.4.6: À esquerda, Kayapo indians. Prime candidates for marriage e à direita Kayapo indians de 1983

Fonte: https://pro.magnumphotos.com/C.aspx?VP3=SearchResult\&ALID=2K1HRGMTTAA

Considerando o trabalho de Miguel no contexto das relações com as instituições, encontramos a possiblidade de problematizar a respeito dos elementos constitutivos de seu trabalho que se revelam como testemunhos de acordos e relações sociais dentro do próprio campo das artes. Se por um lado as artes em séculos passados eram entranhadas de convenções comerciais que afetavam as categorias perceptivas, influenciando os artistas que, no mais das vezes, trabalhavam sob encomenda, por outro lado verificamos que, apesar de as relações no campo das artes terem passado por adequações relevantes, nunca deixaram de atender a interesses e apelos de instituições e à influência de atores em posições específicas e estratégicas no campo.

Na sua trajetória, é recorrente Miguel apontar o desejo de não se deixar emoldurar por tendências e parâmetros, mas de seguir de acordo com suas convicções e preferências, um traço de autonomia comum ao campo artístico desde o advento da modernidade. Entretanto é necessário analisar até que ponto essa busca por liberdade e pela produção de uma arte independente não se configura, também, como uma tendência, sobretudo em se tratando da arte contemporânea, na qual os públicos, as instituições e o mercado esperam justamente pela transgressão, pelo inusitado.

No Instituto Inhotim, por exemplo, Miguel Rio Branco divide espaço com outras galerias de artistas nacional e internacionalmente aclamados, que de certa forma foram legitimados por atenderem a convenções e anseios das instituições validadoras. Ao lado de Adriana Varejão, Tunga, Cildo Meireles, 
Hélio Oiticica, Matthew Barney, Giuseppe Penone, Chris Burden, Olafur Eliasson e tantos outros nomes consagrados, Miguel Rio Branco tem um pavilhão permanente no parque que abriga diversas de suas obras, um sinal de que, para certas propostas curatoriais, seu trabalho dialoga com os demais ali presentes.

Após a grande importância dada ao enfoque biográfico na pesquisa sociológica, na década de 1980, nos moldes propostos por Daniel Bertaux, Pierre Bourdieu (1986) lança uma crítica ao seu método no sentido de aferir a ausência de uma necessária objetivação dos dados. Propõe, então, que o uso de histórias de vida como método fosse substituído pelos estudos de trajetórias considerando tal noção

como série de posições ocupadas por um mesmo agente (ou um mesmo grupo)
em um espaço ele mesmo em devir e submetido a incessantes transformações.
Tentar compreender uma vida como uma série única e suficiente em si mesma
de eventos sucessivos sem outra ligação que a associação a um 'sujeito' cuja
constância é apenas aquela de um nome próprio é quase tão absurdo quanto
tentar explicar um trajeto no metrô sem levar em conta a estrutura da rede, ou
seja, a matriz das relações objetivas entre as diferentes estações (Bourdieu,
1986: 71).

Dessa forma, podemos considerar que o caminho investigativo aqui percorrido é algo próximo ao desejo de objetivação proposto por Bourdieu ao se partir da biografia do artista, colhida em diversas fontes, porém sem desconsiderar fatores externos que o acompanharam e o acompanham ao longo de sua vida. Fatores estes que passaram a figurar em (e influenciar) sua produção artística, de uma maneira ou de outra. Miguel compara seu trabalho artístico ao da costura, uma "costura sem fim" (Persichetti, 2008: 18). Lembra também a ocasião de uma pequena exposição fotográfica na Agência Magnum, no ano de 1980, em que o fotógrafo norte-americano Dennis Stock fez a seguinte analogia acerca de sua obra: "Seu problema é que você quer fazer música com fotografia"38. Essa comparação, ao invés de contrariá-lo, fêlo considerar um elogio, pois a dinâmica que emprega em suas imagens, as variações em seus trabalhos, que o fazem, pelo visto, ter a destreza de um compositor, são tão importantes quanto as imagens em si. Ao falar na pluralidade das linguagens as quais Miguel rege em seu microcosmo, abordamos um outro destaque de sua habilidade com as imagens em sua trajetória: o trabalho cinematográfico, manifesto na direção de alguns filmes

\footnotetext{
38 Cf. http://cultura.estadao.com.br/noticias/geral,miguel-rio-branco-enfatiza-conexoes-da-fotografia-
} com-outras-areas, 1158212 
experimentais e na direção de fotografia de outros. Miguel dirigiu 14 curtasmetragens e fotografou sete longas metragens ${ }^{39}$, dentre os quais o filme de Otavio Bezerra, Uma avenida chamada Brasil, de 1988.

Na década de 1970, quando morou em Nova York, hospedando-se na casa de Hélio Oiticica, tendo tomado emprestada a câmera do amigo que o acolhia, Miguel empreende seus primeiros experimentos fílmicos. Na mesma época, ao passar seis meses no Rio de Janeiro para estudar na ESDI, e no contato com Afonso Beato ${ }^{40}$ e Lauro Escorel, começou a fazer fotografia para o cinema, o que em seguida lhe daria contato com o universo da montagem cinematográfica. Foi nesse período que Rio Branco foi convidado para fazer a fotografia de cena do filme Pindorama (Figuras I.4.7), de Arnaldo Jabor. O filme foi rodado em Itaparica, onde Miguel permaneceu por três meses 'clicando' numa experiência que considera "uma verdadeira escola da fotografia já conectada ao cinema"41. Segundo Rio Branco, "era uma situação em que você aprendia fazendo, uma situação muito comum no Brasil, de você aprender as coisas já na prática sem ter que fazer um curso" (Arnaldo Jabor, 2012).
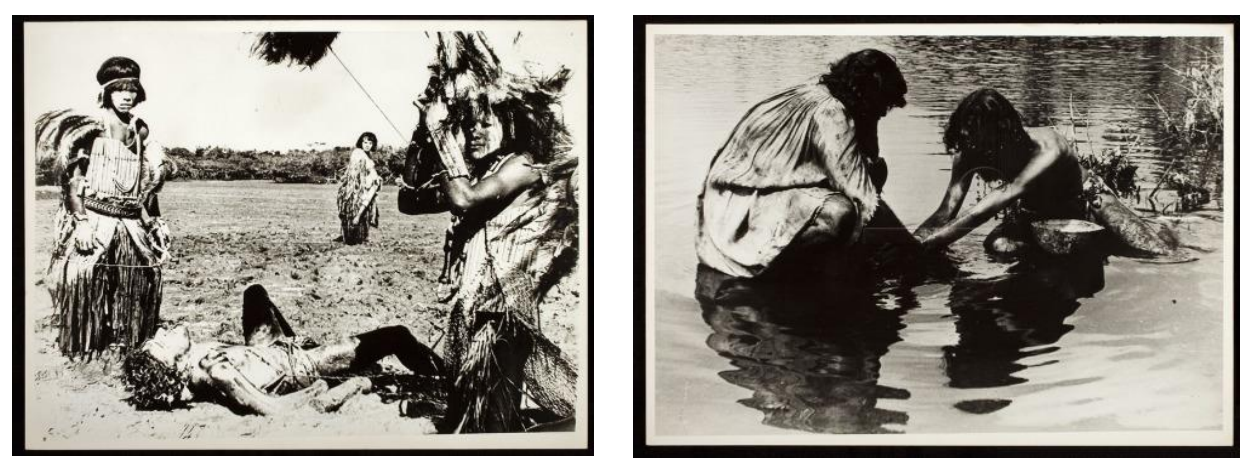

Figuras I.4.7: Fotografias do filme Pindorama de Arnaldo Jabor e fotografia de Miguel Rio Branco

Fonte - http://www.bcc.org.br/fotos/galeria/003438?page=1

No final dessa intensa década de 1970, por um período de três anos Miguel Rio Branco empreendeu um trabalho fotográfico no Pelourinho, alvejando com suas lentes as prostitutas do Maciel e o dia a dia da comunidade que ali vivia, e que considerava banal o que ali acontecia, a

\footnotetext{
${ }^{39}$ Informações colhidas da página web do artista. Cf. http://www.miguelriobranco.com.br/portu/biografia.asp.

${ }^{40}$ Fotógrafo, diretor e professor de fotografia que lecionava na ESDI à época em que Miguel Rio Branco estudara na instituição.

41 Relato feito a uma entrevista cedida à Revista Arte \& Ensaios, de agosto de 2012. Cf. https://www.ppgav.eba.ufrj.br/wp-content/uploads/2014/05/entrevista-Miguel.pdf
} 
respeito dos hábitos e da dinâmica social que se construía naquele local. Tais aspectos foram evidenciados pela estética do olhar de Miguel de maneira muito contundente e peculiar. São diversas as facetas no imaginário de Miguel Rio Branco, dentre as quais, a recorrência de temas da realidade social, contudo não unicamente e/ou prioritariamente num viés de denúncia, mas antes como uma forma de resistência estética que supera um simples olhar engajado com as causas sociais apenas, para propor a urgência de um novo olhar pelo qual se possa construir novas realidades.

Miguel, nas fotografias das prostitutas do Maciel (Figuras I.4.8), se coloca como sujeito deflagrador de uma realidade em ruínas, e ao fotografar aqueles corpos nus, fogosos, insinuantes, marcados, saturados, chagados, não o faz sem ter a consciência e o conhecimento da natureza e da dinâmica daquele local ao qual adentrara para trabalhar. As experiências de contato do olhar do observador com as imagens de Miguel Rio Branco são uma reconfiguração do contato que ele próprio protagoniza ao se dar nas experiências necessárias para fazer as fotografias que busca. Talvez por isso seja tão recorrente a presença, em suas imagens, da pele de pessoas, do couro de animais, da superfície de objetos, das texturas (reconhecíveis e irreconhecíveis). Nelas, Miguel demonstra a intimidade que busca com a categoria fronteira, sendo a pele a primeira fronteira do ser, como a estrutura que nos separa do mundo ao nosso redor, mas que também - e ao mesmo tempo - nos coloca em contato com esse mesmo mundo, pois é nessa instância - a pele - onde as trocas sensoriais se potencializam.
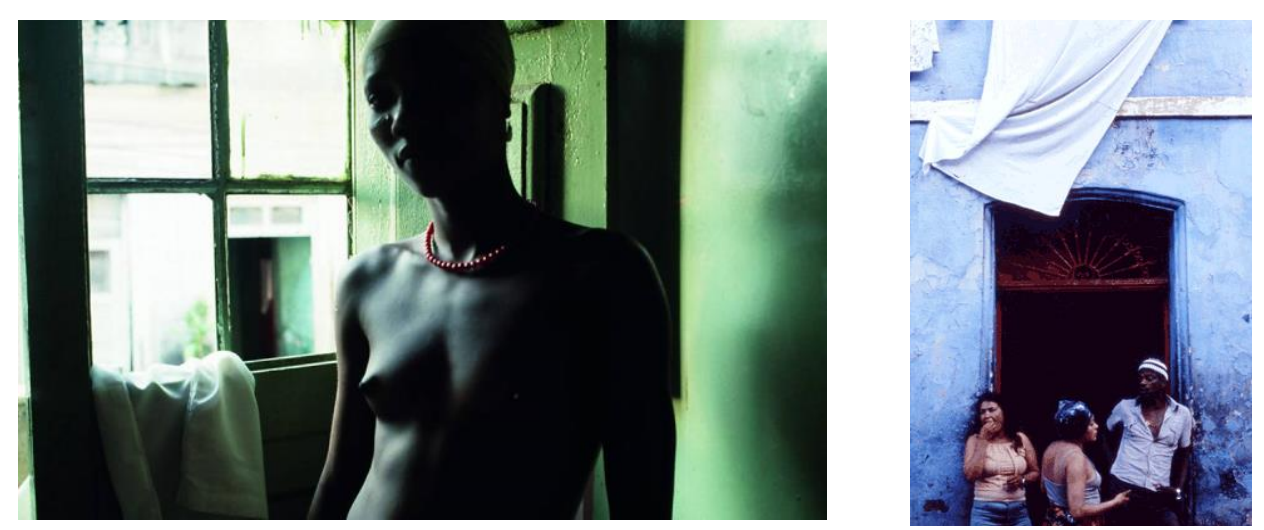

Figuras I.4.8: Fotografias da série Maciel feitas por Miguel Rio Branco na parte mais antiga do Pelourinho

Fontes:

https://www1.folha.uol.com.br/paywall/signup.shtml?https://www1.folha.uol.com.br/ilustrada/2017/07/1899 695-masp-exibe-serie-classica-de-miguel-rio-branco-sobre-bordeis-em-salvador.shtml 


\section{Miguel: suas montagens e fusões}

Seguindo adiante com suas propostas de experimentação, Miguel Rio Branco, ao deparar-se com todo o material imagético garimpado naquele período no Pelourinho, alavanca com a realização, nas nascentes da década de 1980, do filme Nada levarei qundo morrer aqueles que mim deve cobrarei no inferno ${ }^{42}$ (Figuras I.4.9), uma película de curta metragem (19 minutos) que resulta de um trabalho de edição em que o artista reúne em camadas áudios, fotografias e filmagens - imagens em movimento do dia a dia da comunidade do Maciel. O trabalho audiovisual toma forma pela sobreposição de peles diáfanas: tanto as imagens quanto a trilha sonora compõem um ritmo ritualístico, no qual as percepções vão se fundindo e nossos sentidos são, por vezes, sabotados ou pela surpresa e pela irreverência, ou pela presença de momentos em que não encontramos significação imediata. Essa desordem transmite um sentimento de depressão, de desesperança, de angústia e de ignomínia, sob a construção de um universo com um código de ética bem peculiar, a saber: crianças presenciando casais excitando-se; deflagrações de atos sexuais em si; sons de gemidos; pessoas completamente nuas; mulheres com corpos degradados; etc.
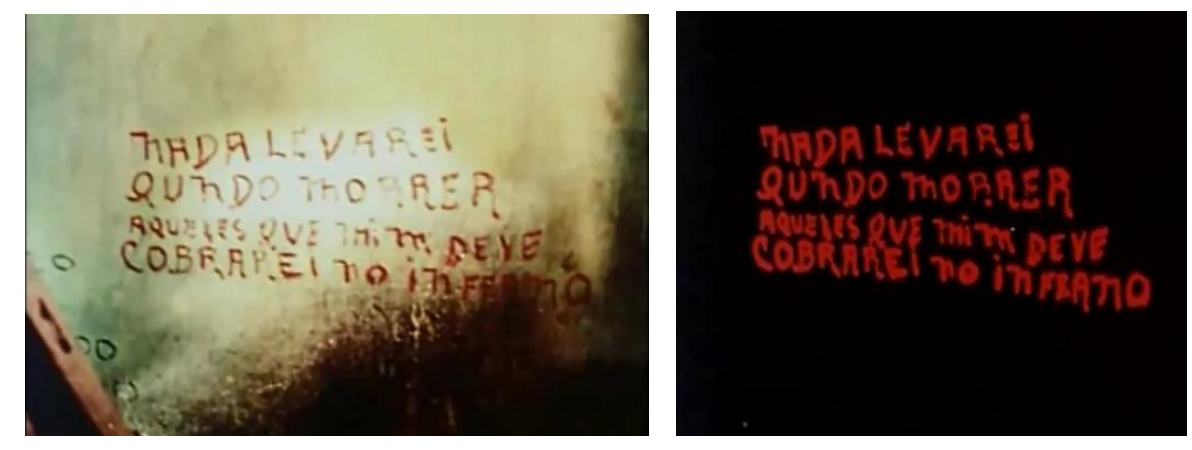

Figuras I.4.9: Frames do filme Nada levarei qundo morrer aqueles que mim deve cobrarei no inferno

Fonte: https://www.youtube.com/watch?v=UjMwMSGgsIA

\footnotetext{
42 O título faz referência a um letreiro amador com o qual se deparou, uma inscrição que trazia esta expressão tal e qual a utiliza para dar nome à curta metragem. Por vezes, seu nome aparece assim como no letreiro, ocultando, inclusive o "a" de "quando", expondo a forma "qundo". Em algumas outras fontes, o nome parece ter sido corrigido, utilizando-se o "quando", diferente de como está no letreiro. Em outras, como no site do Instituto Inhotim, o nome do filme aparece com as devidas correções gramaticais e ortográficas: Nada levarei quando morrer, aqueles que me devem cobrarei no Inferno. O filme - premiado, em 1982, no XI Festival Internacional du Fillm de Court Métrage et du Film Documentaire, em Lille, na França (recebendo o Prêmio especial do juri e o Prêmio da crítica internacional), e em 1981 no Festival de Cinema de Brasília (recebendo o Prêmio de melhor fotografia) - está em exposição permanente em uma sala do pavilhão Miguel Rio Branco no Instituto Inhotim, em Brumadinho-MG.
} 
Assim, as relações de Miguel Rio Branco com projetos de linguagens múltiplas começam a alargar as possibilidades e a encontrar, em tais experiências - tanto com a realização audiovisual e a fotografia para o cinema, quanto com a montagem e a edição de tais imagens - o acercamento de um método próprio de construção imaginativa. Miguel traça seu percurso de uma forma em que não se limita apenas ao documental ou à crítica social, mas que proporcione uma estrutura poética criadora de um algo além, que esteja impedido de ser definido por padrões estéticos delimitados por tal ou tal tendência, escola, artista ou conceito, segundo sua perspectiva. Prefere, com suas imagens, compor poemas visuais, como menciona em algumas entrevistas para referir-se à sua preferência pela contaminação que a montagem traz: "Ao invés de se ter uma palavra, se tem uma frase" 43 , diz.

Por vezes Miguel menciona "eu acho que sou um poeta visual com a frustração de não ser músico, talvez..."44, comparando-se a um compositor, tanto com relação à criação de ritmos e de arranjos visuais, quanto seu gosto e afinidade com o trabalho de paisagem sonora, já que utiliza música/sons em boa parte de seus trabalhos, o que imprime uma atmosfera peculiar às suas obras. Além da arquitetura, do cenário, do ambiente e da imagem, a música tem uma importante função estética nas propostas artísticas de Miguel Rio Branco, sobretudo nas instalações.

Não é de surpreender que a partir do início dos anos 1980, Miguel passe a conceber formatos de exposição que fugiam a certos padrões, misturando a fotografia com a collage - tal como fazia com a pintura - nas elaborações expositivas, por exemplo, montando painéis de fotografias coladas em papel carne seca que ficavam suspensos criando uma espécie de pequeno labirinto por onde o público precisava passar para poder ver as imagens. Esse trabalho, uma série de fotografias feitas em Carnaíba - BA, em um garimpo de esmeraldas, fora exposto na Escola de Artes Visuais do Parque Lage (1978) e no Museu de Arte de São Paulo (1979). Depois, em vários outros locais, compondo exposições de coletâneas do artista, como a que fora feita numa galeria em Groningen, na Holanda, em 2008, em uma série chamada Negativo Sujo, que reunia, além dos trabalhos fotográficos, o cinema e as impressões em materiais diversos - como o tecido voil. Os

\footnotetext{
43 Entrevista concedida por ocasião da abertura de sua exposição Teoria da Cor, na galeria Paulo Darzé (http://www.paulodarzegaleria.com.br/) em Salvador - BA, em maio de 2010. Cf. https://www.youtube.com/watch?v=29bPKE41W_E

${ }^{44}$ Menciona isso em algumas ocasiões de entrevista, como é caso da anteriormente citada.
} 
trabalhos reunidos na série foram, dentre outros, Nada levarei qundo morrer, e as montagens Entre os olhos o deserto e Out of nowhere.

A opção do artista pelas narrativas não lineares concretizadas pelas montagens com as quais foi criando bastante afinidade, o inseriu num viés que o levou a produzir, em sua obra, uma das expressões mais significativas de sua carreira: as instalações artísticas. Miguel reúne aí tanto todo seu esforço e material visual, quanto seu empenho para a criação de amontoados imagéticos que dialogam com nossos sentidos através da arquitetura, da música, das projeções, da luz, dos objetos que utiliza e das próprias imagens, sozinhas ou em arranjos duplos ou triplos. É por este caminho que há mais de 20 anos Miguel desprivilegia uma construção que mostre a evidência de conexão entre as imagens e outros elementos, para privilegiar uma narrativa própria do espaço, e nisso, o próprio público acaba se tornando um elemento da composição, da montagem, já que precisa adentrar à obra para vê-la, observá-la, fruí-la, vivê-la.

Em 1983, na Bienal de São Paulo, Miguel expõe a instalação Diálogo com Amaú, uma sala com cinco telas transparentes (em tecido voil) em que se podia ver o dentro e o fora, uma experiência em que era possível enxergar o através. A leveza do material conjugada com a luz das projeções davam ao espaço uma fluidez onde o público é convidado a mergulhar. Nas imagens fotográficas projetadas, uma série: o trabalho de registro em que Miguel fotografou um índio surdo e mudo. Em 2007, na Galeria Millan, também em São Paulo, Rio Branco expõe Dislecsias, Epileptronic. A primeira - Dislecsias - faz um resgate de seu trabalho em preto, branco e cinza, o que de certo modo impactou por ser a exposição de um fotógrafo aclamado pela forma expressiva e original com que trabalha a cor na fotografia. Entretanto, revisitando seus arquivos, Miguel resolve expor apenas trabalhos em grayscale tanto propondo um desafio insolúvel para quem tentar percebê-la como uma narrativa linear e formal quanto conclamando a obliterar a razão em nome de uma investigação de natureza sensorial.

Já no andar de cima da galeria, Miguel monta e exibe a instalação Epileptronic, usando 'sucatas tecnológicas'. Sobre a exposição, o curador Eder Chiodetto diz que "a luz tênue que emerge do chão confere um clima quase religioso. Obra mutante, ora remete a um oratório, ora a imagem que os satélites fazem das grandes metrópoles, ora a uma cidade atingida por um 
bombardeio." 45 A exposição consiste na justaposição de elementos - como a presença, por exemplo, de dois tubos televisivos suspensos que exibem peixes nadando em espécies de aquários virtuais - que sugerem o ritmo com que somos acometidos pela necessidade de aparatos tecnológicos para nos tornarmos inseridos na sociedade, e de como esses artefatos deveriam nos ajudar a pensar melhor o viver de forma mais harmônica em sociedade. Entretanto, a velocidade e a fugacidade que gere o ritmo das invenções tecnológicas acabam por servir a outros interesses que não o de suscitar uma reflexão sobre a sociedade mais humanizada e menos racional.

Essa exposição torna-se um bom exemplo da relação de fusão das coadjacências que se podem encontrar na obra de Miguel Rio Branco. Dislecsias, Epileptronic ${ }^{46}$ (Figuras I.4.9) é composto por dois trabalhos, grosso modo: uma exposição fotográfica e uma instalação. Para o fotógrafo, o termo dislecsia está longe de se referir apenas a uma doença, é uma maneira diferente de ver o mundo, e no caso, uma maneira não-descritiva e não-linear de vê-lo. Nesse trabalho, Miguel parte da proposta poética de percebermos 0 mundo e construir nosso olhar de maneiras diferentes, não dadas, e faz isso por meio do esforço, não inédito em sua história artística, de recorrer aos seus arquivos. Com ele, criam-se camadas de temporalidades - por estarmos tratando de arquivos - que no andar superior chegam ao termo: na instalação Epileptronic, as camadas saltam da bidimensionalidade, e as reentrâncias imagéticas que se tecem para o olhar através das fotografias, ganham uma terceira dimensão ao tornarem-se objetos, artefatos e sucatas permeados por uma tenaz iluminação no andar de cima. A luz parece criar um movimento de imanência de um andar para o outro, compondo uma visualidade que se movimenta entre iluminar fotografias que se dão ao olhar e mesclar em lascas, numa precária racionalidade, os objetos da instalação. A sensação é a de que, ao subir a escada, se é apreendido por uma luz que se vai tornado promíscua, dada aos prazeres de outros sentidos. Miguel empreendeu diversas outras instalações, essas suas formas de ampliação das possibilidades de alargamento imagético, tais como Diálogos com Amaú, 1983; Tubarões de Seda, 2006; Gritos Surdos, 2001; Entre os olhos, o deserto, $1997^{47}$, esta última, em exposição permanente no Instituto Inhotim

\footnotetext{
${ }^{45} \mathrm{O}$ texto escrito pelo curador Eder Chiodetto. Cf.

http://www1.folha.uol.com.br/fsp/ilustrad/fq2003200714.htm

${ }^{46}$ Da instalação Epileptronic, os sites da web carecem de registros fotográficos.

47 Fotografias e vídeos de suas instalações podem ser conferidas no site do artista: http://www.miguelriobranco.com.br.
} 
desde sua inauguração em 2010, tendo sido exposta pela primeira vez em 1997 na Casa de La Cultura de Tijuana, no México, e no mesmo ano no In Site 97, em San Diego, nos USA, sob o título Between the eyes, the desert.

Toda a trajetória artística de Miguel Rio Branco, ou seja, sua própria vida, esteve sempre se cruzando com a presença de diversos artistas brasileiros e internacionais, o que the proporcionou pluralidade na linguagem e multiplicidade de vertentes por onde caminhou com seu trabalho fotográfico e audiovisual, sobretudo na década de 1970 em diante, quando esteve em contato com o cinema, mais intensamente fotografando para diretores como Antônio Calmón, Júlio Bressane, Otávio Bezerra, Zózimo Bulbul, Lucia Murat, Afonso Beato e Wilson Coutinho, como também registros de trabalhos de Hélio Oiticica, em Ninhos de 1971, vídeos como Apaga-te Sésamo, Objetos e Esculturas de Waltércio Caldas, em 1986, e também Trabalho, em 1987, para o escultor José Resende.

Esse cenário contribuiu sobremaneira para o ímpeto experimental de Miguel, que se deixou derivar por meio das linguagens artísticas, não conseguindo mais se conter nos limites impostos pela fotografia fotoclubista de anos anteriores ou pelos parâmetros de sequências narrativas que o vídeo estava propondo. Assim, influenciado também pela tendência mundial daquela década que passava pela forte influência da arte conceitual, uma de suas principais preocupações figurava-se em questionar convenções na arte e levantar um debate estético que desviasse os eixos do olhar e das discussões sobre o que é arte. Miguel expandiu as fronteiras do material imagético que tinha em mãos, atomizando-o, potencializando-o.

Nessa discussão, é válido trazer a alcunha fotografia contaminada proposta por Tadeu Chiarelli, e citado por Lívia Afonso de Aquino (2005), segundo a qual o cruzamento entre linguagens artísticas dava um novo estatuto para a imagem fotográfica, pois novas perspectivas estavam em questão, como a expansão do suporte de exposição para a tridimensionalidade possível dos espaços e dos tempos. É nessa via que buscamos definir as instalações na trajetória artística de Miguel Rio Branco: a potencialização de um argumento sobre o que é arte construído a partir de imagens, levando ao termo as possibilidades que se abrem pela estratificação, acumulação, expansão e exploração de materiais e suportes, espaços e tempos. Sobre a matéria-prima da fabricação desse seu imaginário, Miguel, ao invés de ir buscar sempre novas fotografias para expor, 
reconfigura as que já tem em suas gavetas, ou seja, dá preferência às suas imagens de arquivo, seus trabalhos passados, se permitindo, assim, ao desafio de construir uma nova poética por meio desse jogo de arranjos e possibilidades que é a montagem.

Essa exposição textual é o esforço, pela análise de documentos (escritos, mas também, e sobretudo, imagéticos), de criar um imaginário da vida do artista, que torne-se uma realidade que deixa de ser unilateral para ser um "objeto apreendido através de correspondências fictícias capazes de nos revelar correspondências reais" (Silva, 1992: 18), esclarecendo acerca do conceito repensado de imaginário, abordado pela historiografia inglesa e alemã, que segue por um caminho diverso daquele que liga a palavra imaginário a 'falsidade', 'mentira' ou 'engano' (idem).

No caso, os documentos escritos sobre a vida e a obra do Miguel aos quais acedemos nesse percurso replicam, no mais das vezes, as mesmas informações. Porém, as imagens de suas expressões artísticas (quadros, fotografias, filmes, instalações) permanecem inesgotáveis quanto ao que podem mensurar. Em outro trecho do texto de Silva (1992), referindo-se ao que propõe Rubén Bonifaz Nuno, diz que "monumentos plásticos, grandes e pequenos, estão livres de suspeita de contaminação", e complementa: "permitindo, portanto, que se inicie a compreensão de outros universos cognitivos" (Silva, 1992: 18).

Buscamos compreender essa ausência de contaminações no seguinte aspecto: considerando um caráter aberto da imagem, que nos permite, olhando para ela, ver seus intervalos, ausências e reticências, e aí encontrar o terreno propício para que um novo conhecimento surja. Estar "livre de contaminações", como propõe Silva, é sua reflexão sobre as limitações do documento escrito, da palavra, portanto, em detrimento do discurso da imagem.

\section{Conclusões}

Este capítulo é parte de um trabalho mais amplo desenvolvido no âmbito da pesquisa sobre a significação de instalações artísticas a partir do trabalho de um artista, no caso Miguel Rio Branco. Investigamos por meio de uma pesquisa de observação in loco dos trabalhos do artista, especificamente uma instalação: Entre os olhos, o deserto. A metodologia de análise e compreensão se construiu partindo, em um primeiro momento, da trajetória 
de vida do artista e das relações com fatores externos que constituíram, na sua carreira, uma teia sob a qual pôde elaborar suas preferências estéticas e seu modus operandi. Percebemos, desse modo, que as imagens do trabalho de Miguel Rio Branco formam uma espécie de narrativa biográfica, ou seja, tornam-se o histórico da vida do artista, principalmente e sobretudo pelo fato de que Miguel privilegia o trabalho com os próprios arquivos, que se configuram como testemunhos de sua trajetória.

Sobre a história de vida como uma das noções do senso comum, Bourdieu (1996) considera usual entre os romancistas, e porque não dizer também entre os historiadores, a ideia de uma filosofia da história com o sentido de narrativa histórica, e nesse sentido afirma que tanto uns quanto outros têm métodos equivalentes, ou seja, tratam a história de vida como um apanhado segundo uma ordem cronológica de acontecimentos. No mesmo texto, o autor declara ser o processo de biografar ou autobiografar uma busca da "criação artificial de sentido" (Bourdieu, 1996: 76), pois há uma inclinação natural em ideologizar um percurso de vida ressaltando acontecimentos que se julga importantes - os quais Bourdieu chama de acontecimentos significativos - para a construção de uma teia que cause a impressão de coerência, consistência e constância, ainda que, para isso, o biógrafo recorra à narração de acontecimentos que não estejam encadeados diretamente, mas que mesmo assim tendam a se organizar em sequências inteligíveis.

Entretanto, o autor considera como uma "ilusão retórica" (idem, p. 76) o fato de ceder às tradições literárias que não abrem mão dessa estrutura de significação regida pela ideia de uma sequência coordenada de eventos. Citando Alain Robbe-Grillet ${ }^{48}$, Bourdieu afirma sua hipótese:

o advento do romance moderno está diretamente vinculado a esta descoberta: o real é descontínuo, formado por elementos justapostos sem razão, cada urn é único, e tanto mais difíceis de entender porque surgem sempre de modo imprevisto, fora de propósito, de modo aleatório (Robbe-Grillet in Bourdieu, 1996: 76).

A aleatoriedade evocada por Robbe-Grillet, mencionada por Bourdieu e onde ele construirá sua crítica, contrasta com a possibilidade da construção do apanhado dos acontecimentos da vida de alguém, ou seja, de sua própria história de vida, como uma elaboração que, ainda que por vias do anacronismo e da descontinuidade, não comprometa o sentido e a

\footnotetext{
${ }^{48}$ Esta citação está contida no texto bourdiesiano em questão ( $A$ ilusão Biográfica, in Razões Práticas: Sobre a teoria da ação), mas originalmente seu texto fonte é Le miroir qui revient. Paris, Minuit, A. Robbe-Grillet, 1984: 208.
} 
notoriedade do que se quer transmitir sobre a vida de outrem. Tanto biógrafos quanto autobiógrafos têm se preocupado (e concordado entre si) em atribuir sentido às interpretações dos fatos que mencionam ou mencionarão, quer seja numa entrevista, num trabalho escrito, num filme (documentário, fatalmente, mas não obrigatoriamente). Entretanto, Bourdieu levanta a questão de que o abandono da linearidade romanesca tenha coincidido com uma questão que se refere a uma desconstrução da história: o questionamento da visão da vida como existência dotada de sentido - tanto no sentido de significação quanto de direção (Bourdieu, 1996: 76). E aqui, Bourdieu empreende sua crítica:

Produzir uma história de vida, tratar a vida como uma história, isto é, como a narrativa coerente de uma sequência significativa e coordenada de eventos, talvez seja ceder a uma ilusão retórica, a uma representação comum da existência que toda uma tradição literária nos deixou e não deixa de reforçar. (Bourdieu, 1996: 76).

Dessa forma, nos utilizamos das reflexões que o autor francês faz acerca da história de vida e do esforço - que considera estéreo - por inteligibilidade advindo de aparatos totalizantes e unificadores, como o da tradição literária, para refletir sobre uma vida contada por meio de imagens. O trabalho imagético de Miguel Rio Branco reuniu, ao longo dos anos, as marcas de temporalidades: temporalidades cruzadas, por assim dizer, quando consideramos que o artista reutiliza - dando novo significado imagens antigas de seu acervo como se tivessem sido feitas para um projeto presente. A facilidade com que manipula suas imagens e as transforma em trabalhos atuais, conectados com o seu tempo, e com larga significação no contexto artístico, social e cultural aponta para um caráter peculiar de seu imaginário: Miguel recria-se a cada nova proposta artística, e o faz a partir de uma matéria-prima sintomática que é suas próprias imagens.

Outro aspecto salientável a partir desse artigo é a posição de Miguel no campo das artes. Normalmente é mencionado como um artista/fotógrafo representante do imaginário artístico brasileiro. Os vários prêmios e homenagens que recebeu ao longo de sua carreira, devidamente registrados em sua ficha técnica, são sinais da legitimação e do lugar ocupado por Miguel nesse campo no qual forças interagem, diversas vezes anulando, outras vezes reforçando certos vetores. O fato é que Rio Branco tem um lastro histórico de aprovação e reconhecimento, o que confere sentido ao fato de ter, ao longo da vida de artista, reforçado seu método de trabalho, já que as instituições sempre apontaram positivamente para o resultado de seu labor. 
Miguel Rio Branco é artista por profissão, não precisando, aparentemente, ter outras vias financeiras para manter-se como, por exemplo, ser professor, escritor, pesquisador. É seu próprio trabalho artístico que o tornou autônomo para fazer sua obra da maneira que deseja. O que, entretanto, não atesta emancipação com relação às regras do jogo, já que os próprios títulos, prêmios, entrevistas apontam para adequações e compatibilidades de uma carreira que parece ser o que o mercado, as instituições reguladoras e os agentes estratégicos do campo desejam.

\section{Referências Bibliográficas}

Aquino, L. A. De (2005). Imagem-poema: a poética de Miguel Rio Branco. Dissertação de Mestrado - Universidade Estadual de Campinas. Instituto de Artes.

Bourdieu, P. (1996). A ilusão biográfica. In Razões práticas: sobre a teoria da ação. Campinas, SP: Papirus.

Chiarelli, T. (2002). Arte Intemacional brasileira, pag. 115. Sao Paulo: Lemos.

Heinich, N. (2008). Para acabar com a discussão sobre arte contemporânea. In Bueno, M. L. \& Camargo, L. O. de L. (org.). Cultura e consumo: estilos de vida na contemporaneidade. São Paulo: Editora Senac São Paulo.

Monteiro, C. (2013). Pensando sobre História, Imagem e Cultura visual. Patrimônio e História. UNESP, São Paulo, Julho - Dezembro. (Disponível em: http://pem.assis.unesp.br/index.php/pem/article/view/410).

Persichetti, S. (2008). Migue/ Rio Branco. São Paulo: Lazuli Editora.

Silva, J. (1992). O paraíso perdido: descrição. Revista da Universidade de São Paulo. 